\title{
Un ejemplo de interpretación multinivel en materia urbanística. Comentario del caso Santa Cruz con Municipalidad de Vitacura
}

\section{An example of multilevel urban planning interpretation. Commentary of the case Santa Cruz v. Municipality of Vitacura}

Giannina Bocchi Jiménez*

En materia urbanística encontramos hasta cinco niveles de órganos -tanto de naturaleza administrativa como jurisdiccional- con facultades interpretativas, lo que denominamos interpretación multinivel, que plantea serios problemas en esta área del Derecho.

Palabras clave: Urbanismo, Interpretación, Contraloría, Tribunales.
Urban planning matters present up to five levels of authorities -whether of administrative or jurisdictional naturewith interpretation powers, which we call multi-level interpretation, leading to serious problems in this field of the Law.

Keywords: Urban planning, Interpretation, National Comptroller, Courts.

\section{Introducción}

En este trabajo examinamos la sentencia de la Tercera Sala de la Corte Suprema en los autos caratulados Santa Cruz Eyzaguirre Juan y otros con Municipalidad de Vitacura'. El caso dice relación con un reclamo de ilegalidad interpuesto en contra de la DOM de la Municipalidad de Vitacura por haber otorgado un permiso de edificación el cual se autorizó la construcción de un edificio de oficinas en dicha comuna.

A propósito de esta decisión podremos observar lo que denomino interpretación multinivel en materia urbanística y los problemas que este fenómeno plantea en esta área del Derecho Público.

\footnotetext{
* Licenciada de la Pontificia Universidad Católica de Chile, Santiago, Chile. Magister en Derecho (c), Universidad de Chile. Correo electrónico gianninabocchi@gmail.com. Dirección postal: Av. Libertador Bernardo O'Higgins N³40, Santiago de Chile.

1 Santa Cruz Eyzaguirre Juan y otros con Municipalidad de Vitacura (2020).
}

Artículo recibido el 4 de noviembre de 2021 y aceptado el 17 de diciembre de 2021. 


\section{El caso de autos: un ejemplo de interpretación multinivel}

Para entender el alcance de la controversia, debemos tener presente los siguientes hechos fijados por los jueces del fondo en la causa.

1. El DOM otorgó el certificado de informaciones previas para el inmueble del proyecto, señalando que el uso de suelo es exclusivo de vivienda.

2. La inmobiliaria solicitó la aprobación de un anteproyecto de edificación para la construcción de un edificio de oficinas.

3. El DOM emitió un acta de observaciones, entre las que se encuentra el incumplimiento de las normas de uso de suelo establecido en el artículo 43 cuadro 48 del PRC².

4. Al no haber ia Inmobiliaria subsanado la totalidad de las observaciones, el DOM rechazó la solicitud de anteproyecto.

5. La inmobiliaria impugnó ante la CGR el acta de observaciones, sobre la base que el uso de suelo que contempla el cuadro 48 del artículo 43 del PRC vulnera lo dispuesto en el artículo 2.1.33 de la OGUC 3 .

6. La CGR, previo informe de la Subsecretaría y Seremi, emitió el Dictamen $N^{\circ} 11.765$ de 2017, estableciendo que las normas impugnadas del PRC se apartan de la LGUC y de la OGUC, de modo que en la zona en cuestión sí está permitido el uso de suelo equipamiento, por lo que la observación efectuada por la DOM acerca de este aspecto debe ser dejada sin efecto, estando obligada a rectificar el acta de observaciones. Además, ordena modificar su PRC para que se ajuste a la normativa vigente y que mientras procede de esa forma, debe abstenerse de aplicar el citado cuadro 48 del artículo 43.

7. En base a lo anterior, la DOM inició un procedimiento de invalidación de la resolución que rechazó el anteproyecto, invalidándola finalmente. Asimismo, rectificó el acta de observaciones, eliminando la observación sobre la cual versó el Dictamen $N^{\circ} 11.765$, esto es, la falta de aplicación del cuadro $\mathrm{N}^{\circ} 48$ del artículo 43 del PRC.

8. Finalmente, la inmobiliaria subsanó las observaciones restantes, por lo cual el DOM aprobó la solicitud de anteproyecto y, posteriormente, el Permiso, correspondiente a un edificio de oficinas.

La Corte de Apelaciones de Santiago rechazó un reclamo de ilegalidad de los vecinos en contra del permiso relativo a esta causa ${ }^{4}$, por lo que interpusieron el recurso de casación en el fondo en contra de la sentencia.

\footnotetext{
2 Resolución N 59, de 1999 del Gobierno Regional Metropolitano de Santiago.

3 Indica las clases de equipamiento.

4 Santa Cruz Eyzaguirre Juan y otros con Municipalidad de Vitacura (2019).
} 
Por su parte, la Corte Suprema, luego de situar la controversia dentro del Derecho Urbanístico y sus características principales, subraya la obligatoriedad de los IPT en todos sus niveles, tanto "para los órganos de la Administración como para los particulares", añadiendo que la LGUC "contempla un procedimiento especial para el caso de modificación del mismo contenido en el artículo 43 de dicho cuerpo legal" ${ }^{5}$. Por otro lado, agrega que los pronunciamientos de la CGR "son obligatorios para los organismos de la Administración estatal afectos a su control [...] Sin embargo, no son vinculantes para los tribunales"6. De hecho, no se queda ahí, sino que recuerda que la CGR debe someter su actuación a la Constitución y a la ley, respetando el principio de legalidad, "correspondiendo a los tribunales de justicia verificar y ejercer el control jurisdiccional de sus actos a través de las acciones contencioso administrativas que se interpongan"7.

Sentado lo anterior, la Corte expresa que los jueces del fondo incurrieron en los errores de derecho que reprochan los reclamantes, puesto que el Permiso se vio "afectado por el vicio denunciado [...] en tanto no pudo ser concedido porque no se ajustó a la normativa vigente a la fecha de su otorgamiento -y hasta la presentación del reclamo-, esto es, el artículo 43 cuadro $N^{\circ} 48$ " del PRC, lo que había sido advertido por la misma DOM en el certificado de informaciones previas y en el acta de observaciones, cuando:

expresamente señaló que la zona donde se pretendía emplazar el edificio de oficinas, no permitía dicha construcción atendido el uso del suelo que la norma reglamenta8.

Por lo que esta circunstancia siempre estuvo en conocimiento de la inmobiliaria9. Por estas razones, el Permiso adolece de ilegalidad, ya que "no aplicó el Plan Regulador Comunal vigente a la data de presentación de la solicitud"10. Continúa el razonamiento de la Corte, para que un permiso de edificación:

genere los efectos de imperatividad, obligatoriedad y exigibilidad, propios de su naturaleza, es necesario que su contenido se ajuste a la Constitución y a las normas dictadas conforme a ella, es decir, debe [...] enmarcarse dentro del principio de legalidad ${ }^{11}$.

Lo que no se verificó con la emisión del Permiso. Por estas consideraciones, finalmente, acoge el recurso de casación, puesto que con la actuación del DOM:

\footnotetext{
5 Santa Cruz Eyzaguirre Juan y otros con Municipalidad de Vitacura (2020), c. $13^{\circ}$

6 Ibíd., c. $14^{\circ}$.

7 ldem.

8 Santa Cruz Eyzaguirre Juan y otros con Municipalidad de Vitacura (2020), c. $15^{\circ}$

9 Ibíd., c. $16^{\circ}$

10 Ibíd., c. $18^{\circ}$

11 Ibíd., c. $19^{\circ}$.
} 
se validó un permiso de edificación [...] que desconoce el ordenamiento jurídico vigente a la fecha de la presentación de la solicitud de aprobación del anteproyecto [...] quebrantándose los niveles jerárquicos que constituyen el Derecho Urbanístico, dejando de aplicar una norma reglamentaria vigente ${ }^{12}$.

Ante este fallo, que en los hechos significó que el proyecto dejó de contar con un permiso de edificación vigente, la DOM resolvió paralizar las obras $^{13}$. Debemos destacar que, a la fecha de la sentencia, el proyecto tenía completada su obra gruesa ${ }^{14}$.

Finalmente, la solución a la que fue posible llegar fue en que la inmobiliaria solicitó un nuevo permiso de edificación para la obra ya ejecutada, esta vez, con destino habitacional, lo que se conforma con la actual regulación que el PRC da a la zona ${ }^{15}$.

\section{El problema: la interpretación multinivel}

En los últimos años hemos sido espectadores de controvertidas decisiones de la CGR y de los tribunales superiores de justicia que han resuelto materias propias de la planificación urbana y de las autorizaciones otorgadas conforme a ella ${ }^{16}$, materias altamente técnicas, para las cuales, como es obvio, la formación académica de abogado no nos prepara. Sin embargo, ello no ha sido impedimento para que abogados, tanto del Poder judicial como aquellos que ejercen la profesión en la CGR, se dediquen a una labor bastante compleja: resolver, ya sea en sede administrativa o jurisdiccional, aquellas controversias regidas por el llamado Derecho Urbanístico.

Al mismo tiempo, a los arquitectos proyectistas y revisores independientes no solo se les exige el conocimiento del IPT respectivo y de la normativa contenida en la LGUC y en la OGUC, sino que el éxito de su labor (esto es, de la emisión de un anteproyecto y permiso de edificación jurídicamente inobjetable) depende muchas veces de su dominio de la jurisprudencia administrativa y judicial, así como de la interpretación administrativa que emana del Ministerio de Vivienda y Urbanismo, a través de la DDU y de las respectivas Seremi.

En efecto, en Derecho Urbanístico nos encontramos no con uno, sino con tres o más niveles de órganos con facultades interpretativas. En efecto, si la DOM otorga permisos y anteproyectos (artículos $5^{\circ}$ y $9^{\circ}$ letra a) LGUC), esta

\footnotetext{
12 Ibíd., c. $20^{\circ}-21^{\circ}$.

13 Resolución N³48, de 2020 de la DOM.

14 Oficio Ordinario N 940, de 2020, de la DOM.

15 Resolución N 104, de 2021 de la DOM.

16 Solo a título meramente ilustrativo, podemos citar los siguientes casos: guetos verticales de Estación Central, Asturias en Las Condes, Parque Pümpin y Mall Barón en Valparaíso, Punta Piqueros en Concón, conjunto armónico Bellavista en Recoleta, etc.
} 
indudablemente debe aplicar la normativa vigente (LGUC, OGUC y el o los IPT respectivos) y, para aplicar, se requiere necesariamente interpretar la norma:

la aplicación de una norma implica de manera necesaria su previa interpretación; y como los entes administrativos están llamados a aplicar normas o a controlar la aplicación que otros hacen de ella, síguese que para el cumplimiento de esta función ellos han de haber interpretado tales normas ${ }^{17}$.

De lo anterior, Guzmán Brito deduce que existe "una suerte de facultad difusa de interpretación en todo el funcionariado de los servicios públicos"18. Siguiendo a Cordero Vega, podríamos afirmar que esta interpretación es aquella "que toda autoridad tiene para decidir la implementación de la ley y cumplir sus programas públicos (interpretación inherente o inevitable)"19. También la DDU del Ministerio de Vivienda y Urbanismo está dotada de la potestad para interpretar, impartiendo instrucciones para la aplicación de la LGUC y la OGUC a través de circulares (artículo $4^{\circ}$ primera parte LGUC). Luego, el legislador expresamente otorga a las Seremi la atribución de interpretar los IPT (artículo $4^{\circ}$ segunda parte LGUC). Así, estos dos últimos poderes interpretativos están vinculados

con la extensión de la aplicación de la estructura normativa (interpretación implementativa o complementaria), que sería el caso de las atribuciones encomendadas a [...] otros organismos con competencias normativas (p. e., regulación urbanística y Ministerio de Vivienda y Urbanismo), a los cuales la ley expresamente les reconoce esos poderes interpretativos por consideraciones de orden técnico ${ }^{20}$.

No obstante, hay más. Si a la interpretación de los tres órganos anteriores podríamos denominarla como propiamente urbanística, por consistir en la materia que es su objeto de "negocio", debemos añadir la que emana de la CGR, que corresponde a la llamada "interpretación de claridades o certezas", la cual se encuentra "asociada a despejar pasajes oscuros y dudosos en la aplicación de normas" ${ }^{21}$ y la proveniente de los tribunales de justicia, cuyo ámbito de acción abarca todo el Derecho vigente. En este sentido, ambas instituciones cuentan con unidades especializadas, a saber, la División de Infraestructura y Regulación ${ }^{22}$ y la Tercera Sala ${ }^{23}$, respectivamente. Pues bien, es en este sentido que podemos afirmar que la interpretación en materia urbanística es multinivel: no hay una única fuente de la que emane la interpretación, sino que nos encontramos con distintos niveles escalonados en los que

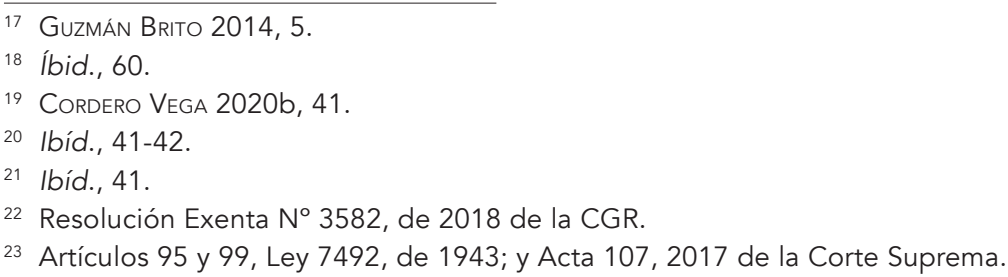


el órgano legalmente encargado de emitir el acto administrativo autorizatorio (DOM) se encuentra en el piso más bajo de esta cadena interpretativa, pudiendo ver revertida su decisión por orden de los niveles superiores (Seremi, DDU, CGR y tribunales de justicia). Hay que notar, eso sí, que a diferencia de todos los demás órganos, la Tercera Sala no cuenta con arquitectos que asesoren a los ministros en el conocimiento y resolución de sus casos, asimismo se distingue en que los llamados a resolver conforme a Derecho son en este caso siempre abogados (ministros o abogados integrantes), mientras que en los otros casos los procedimientos administrativos en materia urbanística están llevados por profesionales de otras áreas, generalmente arquitectos, que pueden tener asistencia de abogados.

En mi opinión, esta interpretación multinivel es problemática, a raíz de la combinación de dos elementos, a saber, (i) la variedad de pareceres que pueden darse en un asunto regido por la normativa urbanística, al existir diversos órganos con competencias concurrentes, por lo que en un caso hipotético podríamos llegar a tener hasta cinco opiniones distintas sobre un mismo asunto (DOM, DDU, Seremi, CGR y tribunales de justicia); y (ii) que la palabra final sobre qué es lo ajustado a Derecho la tiene el órgano jurisdiccional, esto es, aquel cuyos integrantes controlan la actividad de la Administración de acuerdo a todo el Derecho vigente, es decir, no solo la normativa propiamente urbanística, siendo posible también que incorporen otras ramas del Derecho e incluso recurran a otros elementos para resolver (equidad, justicia material, principios generales del Derecho, etc.).

Una dificultad adicional consiste en que la materia urbanística es, al mismo tiempo, considerada por los propios operadores y autoridades competentes como compleja, como lo reconoce la propia DDU cuando explica el sistema de circulares interpretativas del que es emisora:

Este sistema está conformado por dos tipos de circulares, las primeras: que imparten instrucciones sobre la aplicación de disposiciones generales y las segundas: que imparten instrucciones de carácter particular orientadas a dar respuesta a las diversas consultas que ingresan permanentemente a esta División, las que, por la especificidad y características de la materia consultada, tienen incidencia en situaciones puntuales, que no constituyen la aplicación general de una determinada disposición, sino que responden a un aspecto específico cuya aplicación ha generado dudas tanto en las Direcciones de Obras Municipales, Secretarías Regionales Ministeriales de Vivienda y Urbanismo, revisores independientes, profesionales competentes, así como en diversos particulares ${ }^{24}$.

Por consiguiente, la materia es, según la misma DDU, problemática per se: el mismo órgano con competencia para interpretar la LGUC y la OGUC reconoce, expresamente, que hay oportunidades en las que la aplicación de la normativa es incierta. No nos referiremos a este problema en esta ocasión,

${ }_{24}$ Circular Ordinaria N 160, de 2007 de la DDU. 
pero dejaremos planteada la cuestión que, hay algo, en Derecho Urbanístico, al parecer inherente a esta disciplina, que causa problemas de aplicación normativa más allá de lo esperable en otras ramas del Derecho. Si este es un problema de formulación normativa o propio de la naturaleza técnica del Derecho Urbanístico, requiere una investigación en profundidad que no es objeto de este estudio.

Dicho lo anterior, pasaremos a explicar las consecuencias prácticas del fenómeno de la interpretación multinivel, donde podemos observar los problemas que surgen al existir competencias concurrentes de distintos órganos en la materia.

\section{La interpretación multinivel y algunos problemas que genera}

Aldunate y Cordero Quinzacara citando a Kelsen señalan:

la interpretación de una ley no conduce necesariamente a una decisión única, como si se tratara de la única correcta, sino posiblemente a varias, todas las cuales -en tanto son cotejadas solamente con la ley que haya de aplicarse- tienen el mismo valor, aunque solo una de ellas se convertirá en derecho positivo en el acto del órgano de aplicación de derecho ${ }^{25}$.

Como pudimos apreciar, en el caso de autos estamos en presencia de la interpretación multinivel en materia urbanística que hemos comentado antes: (i) la propia de la DOM consignada en el acta de observaciones (referida a la imposibilidad de construir un edificio de oficinas en un predio con uso de suelo exclusivo de vivienda); (ii) la que emana de la Subsecretaría y la Seremi, consultadas por la CGR; (iii) la surgida de la CGR, que revierte el entendimiento de la DOM y le ordena rectificar el acta de observaciones, lo que consecuencialmente la lleva a otorgar el anteproyecto y posteriormente el Permiso; y (iv) la de la Corte Suprema, que revierte el razonamiento de la CGR.

En mi opinión, el germen del problema se encuentra en (iii): si el PRC como acto administrativo goza, en virtud del inciso final del artículo $3^{\circ}$ de la Ley $N^{\circ} 19.880$ de presunción de legalidad, imperio y exigibilidad, el DOM actuó correctamente al observar la solicitud de anteproyecto por no cumplir con el uso de suelo fijado por el PRC. En efecto, para el DOM (y para Inmobiliaria), el PRC goza de presunción de legalidad, ya que ninguna autoridad -ni administrativa ni judicial- hasta el momento en que se emite el Dictamen N 11.765 había declarado la ilegalidad de la norma impugnada ante la CGR por la inmobiliaria. Por ende, podemos afirmar que el DOM obró conforme a la normativa vigente, y, así, no habría reproche que hacerle. Por eso, debemos preguntarnos, ¿es lícito o, al menos, jurídicamente conveniente, que la CGR declare la ilegalidad de una disposición del PRC, esto es, una norma vigente del ordenamiento jurídico, en una instancia no regulada para ello? Ya que lo que ha hecho la CGR al señalar que la norma del cuadro $N^{\circ} 48$ del ar-

25 Aldunate lizana y Cordero Quinzacara 2013, 304. 
tículo 43 del PRC se aparta de la LGUC y de la OGUC, en los hechos, es afirmar que es ilegal, razón por la cual ordena a la DOM abstenerse de aplicar dicha disposición mientras no corrija su IPT:

[d]e este modo, cuando Contraloría objeta en sus dictámenes el contenido total o parcial de un acto, determinando la correcta interpretación de la ley aplicable, reprocha la conformidad del mismo con el sistema legal, de modo que debe corregirse el acto en su origen ${ }^{26}$.

Entonces, lo que logró hacer la inmobiliaria es trabar un procedimiento invalidatorio sui generis del PRC ante la CGR, no ante la autoridad de la cual emana el acto cuestionado (Municipalidad de Vitacura). Sin embargo, como sabemos, la CGR "no tiene potestades para anular un acto, pero sí puede sugerir y -se discute- ordenar su invalidación, obteniendo el mismo resultado"27, por lo que De la Cruz denomina "decisiones cuasi anulatorias" 28 a aquellas que según Cordero Vega consisten en la "dictaminación como un medio legítimo de declaratoria de ilegalidad de un acto administrativo, lo que implica de paso sincerar el rol cuasijurisdiccional que está cumpliendo la Contraloría en la solución de los problemas entre la Administración y los particulares"29.

Múltiples dudas surgen en este punto, por ejemplo, ¿qué sucede con todos aquellos administrados que se encuentran tramitando autorizaciones ante el DOM aplicando la norma cuestionada y que se encuentran de improviso con el Dictamen $N^{\circ} 11.765$ ? ¿Qué pasa con quienes esperan la recepción definitiva de un proyecto invocando esta norma? ¿Acaso no tendrían esos potenciales afectados derecho a presentar sus alegaciones ante la CGR para defender la legalidad del PRC cuestionado? Si se hubiera iniciado un procedimiento invalidatorio de la norma objetada conforme a la Ley $N^{\circ} 19.880$, lo anterior sería un hecho, por disposición del artículo 21 en relación con el artículo 53 de ese cuerpo legal. Entonces, en mi opinión, por la vía de acudir a la CGR, la inmobiliaria logró iniciar una suerte de procedimiento invalidatorio al margen de la Ley $N^{\circ} 19.880$, ya que logró que el pronunciamiento señalara que el IPT, en lo pertinente, se aparta de la normativa aplicable, por lo que debe ser dejado sin efecto. En este sentido, resulta muy apropiada la afirmación de Cordero Vega acerca de la potestad dictaminante de la CGR, la que en su parecer enfrenta, entre otras, la siguiente objeción: "la opacidad del procedimiento para la emisión de los dictámenes, esencialmente por la ambigüedad que mantiene la Contraloría sobre el tipo de procedimiento administrativo que la sustenta $y$, en consecuencia, la aplicación supletoria de la Ley $N^{\circ} 19.880^{\prime 30}$. También De la Cruz trata todo un acápite sobre la inexistencia de garantías procedimentales en lo que se refiera a la

\footnotetext{
Cordero Vega 2013, 269.

7 De la Cruz Millar 2019, 95.

28 ĺdem.

29 Cordero Vega 2013, 272.

30 Cordero Vega 2020a, 126.
} 
toma de razón y a la potestad dictaminante 31 y por algo es de la opinión que existe un "activismo contralor en materia urbanística"32, lo que también sugiere Cordero Vega:

hasta la década de los 90, la Contraloría se irá pronunciando progresivamente sobre cuestiones que involucran a los particulares, poniendo énfasis en los principios procedimentales, extendiendo su función a cuestiones tales como el otorgamiento de pensiones, tarifas y regulación urbana ${ }^{33}$.

Este último hecho es manifestación de un fenómeno más amplio, al que la doctrina se ha referido cuando en términos de denuncia (o al menos de advertencia) señala que la CGR ha ampliado su potestad dictaminante fuera de las materias que su propia ley orgánica le ha entregado:

Mientras el mandato de su ley orgánica era que le correspondía informar en materias de remuneraciones, estatuto administrativo y funcionamiento de los servicios públicos "para los efectos de la correcta aplicación de las leyes y reglamentos que los rigen"; que en relación a las materias de gastos de los fondos públicos debía informar cuando se suscitaren "dudas para la correcta aplicación de las leyes"; que solo sus dictámenes podían hacerse valer como jurisprudencia administrativa; y que, finalmente, no podía informar en asuntos que "por su naturaleza sean propiamente litigiosos" o que estén "sometidos al conocimiento de los Tribunales de Justicia"; la práctica administrativa llevó a la Contraloría a pronunciarse en materias que iban más allá de la aplicación de la ley por parte de los organismos administrativos, transformándose en una jurisprudencia que tendió a resolver conflictos asignativos y, por lo tanto, a transformarse progresivamente en un organismo de solución de controversias, primero al interior del Estado y luego entre los particulares y el Estado ${ }^{34}$.

Por otra parte, el PRC en su redacción a la fecha de la decisión de la CGR tenía catorce años de vida en el ordenamiento jurídico, lo cual a todas luces supera el plazo de dos años de la Ley $N^{\circ} 19.880$ para ejercer la potestad invalidatoria, de forma que se verifica lo que apuntaban Evans y Poblete:

[l]o anterior se ve agravado si consideramos que no existe plazo legal alguno que limite el ejercicio de esta potestad de la Contraloría, de modo que invocándola puede pronunciarse acerca de la legalidad de cualquier acto, sin importar el tiempo que hubiere transcurrido desde su dictación ${ }^{35}$.

De manera análoga, el mandato de la CGR de que la DOM debe abstenerse aplicar la disposición cuestionada del PRC se aparta de lo previsto en

\footnotetext{
31 De la Cruz Millar 2019, 92 y ss.

32 Ibíd., 88.

33 Cordero Vega 2010, 183.

34 Ibíd., 181.

35 Evans Espiñeira y Poblete Ortúzar 2012, 129.
} 
el inciso final del artículo $3^{\circ}$ de la Ley $N^{\circ} 19.880$, que supedita la suspensión de los efectos del acto administrativo a "una orden de suspensión dispuesta por la autoridad administrativa dentro del procedimiento impugnatorio o por el juez, conociendo por la vía jurisdiccional"; ninguna de estas circunstancias se ha verificado ${ }^{36}$, por lo que recobra importancia la indicación de Cordero Vega y De la Cruz en relación a la inexistencia de certeza sobre el procedimiento que rige la potestad dictaminadora de la CGR.

A este respecto, debemos recordar que la doctrina ha entendido que la CGR ha mutado en sus atribuciones interpretativas: si bien esta "se encuentra legalmente acotada a materias propias de derecho administrativo doméstico" 37 , ella

ha ampliado históricamente ese poder interpretativo al derecho administrativo que aplica la Administración Pública, por lo cual se atribuye poderes extensivos, pudiendo alterar por esa vía potestades de interpretación complementarias que la ley expresamente ha otorgado a otros organismos públicos de carácter técnico ${ }^{38}$.

Entonces, en este caso, si la DOM volvió tras sus pasos y ajustó su decisión al pronunciamiento de la CGR y luego esta decisión es revertida en sede judicial, significa evidentemente que la decisión primitiva de la DOM de objetar el uso de suelo del proyecto se encontraba ajustada a Derecho: esta autoridad no hizo más que aplicar el Derecho vigente, esto es, el PRC.

En otro orden, debemos llamar la atención sobre el hecho que la interpretación multinivel no presenta la misma naturaleza en todos los órganos con esta potestad. Partiendo del supuesto que en sede judicial las vías generalmente utilizadas para impugnar actos $u$ omisiones en materia urbanística son genéricas, esto es, no concebidas especialmente para esta disciplina, se recurre a la acción de protección de garantías constitucionales (artículo 20 de la Constitución Política de la República) y al reclamo de ilegalidad municipal (artículo 151 de la Ley Orgánica Constitucional de Municipalidades), a falta de un contencioso administrativo especial.

Pero si la DOM otorga permisos de edificación aplicando el bloque normativo urbanístico (LGUC, OGUC e IPT) junto con la Ley $N^{\circ} 19.880$, al que también recurren la DDU y la Seremi, los tribunales resolverán con todas las herramientas que tienen a su disposición, todos aquellos elementos que el Derecho ofrece para dirimir la controversia. En este sentido, se ha advertido que:

[l]a potestad administrativa de interpretar normas no es amplia o abierta, como las del legislador y del juez. Mientras estos pueden hacer objeto de su interpretación a cualquier ley vigente o norma que haga sus

\footnotetext{
${ }^{36}$ Aunque resulta al menos curioso el lenguaje que utiliza el fallo de la Corte Suprema al expresar que la Inmobiliaria impugnó ante la CGR el acta de observaciones (c. $8^{\circ}$ ).

37 Cordero Vega 2020b, 43.

38 Ibíd., 44.
} 
veces, y el último, además, a cualquier reglamento, decreto supremo o resolución, la potestad interpretativa de un jefe de servicio alcanza únicamente a las normas cuya aplicación le ha sido encomendada al servicio que rige, o cuya aplicación por otros servicios o entidades le corresponde vigilar; y quedan excluidas de esa potestad, por consiguiente, todas las demás normas existentes ${ }^{39}$.

Esto es muy importante -y creo que frecuentemente pasado por altoya que implica que el juez cuenta con todo un universo de normas para resolver una cuestión eminentemente técnica; pudiendo enriquecer su decisión con argumentos provenientes de otras áreas del Derecho en caso que puedan ser aplicables, pero con el riesgo de transformar la naturaleza de la controversia: si la revisión de los órganos administrativos (DOM, Seremi, DDU e incluso $(G R)$ se restringía a la constatación o verificación que un permiso de edificación ha sido emitido de conformidad con el bloque de legalidad urbanístico, los tribunales resolverán si ese acto administrativo en concreto vulnera otras normas que pertenezcan de otras disciplinas del Derecho que puedan ser aplicables al caso en cuestión. Así, por ejemplo, cuando la Corte de Apelaciones conozca de un recurso de protección que impugna un permiso de edificación, no solo revisará si el permiso ha sido otorgado correctamente, esto es, de conformidad con el bloque normativo urbanístico, sino que también se pronunciará sobre si el otorgamiento de ese permiso, en concreto, vulnera alguna garantía de las protegidas constitucionalmente que merecen la protección del artículo 20 de la Carta Fundamental, aspecto, que, como es evidente, se encuentra fuera de las atribuciones de los restantes órganos con competencias en materia urbanística, que deben velar por la correcta emisión del permiso sin respecto a otras consideraciones más que el respeto a la LGUC, la OGUC y el respectivo IPT.

\section{Una posible solución}

En mi opinión, en Derecho Urbanístico debiera existir una norma análoga a la contenida en el artículo $6^{\circ}$ letra $A N^{\circ} 1$ del Código Tributario, que establece la facultad del Director del Servicio de Impuestos Internos de "[i]nterpretar administrativamente las disposiciones tributarias, fijar normas, impartir instrucciones y dictar órdenes para la aplicación y fiscalización de los impuestos", y en el artículo $1^{\circ}$ del Decreto con Fuerza de Ley $N^{\circ} 7$ de 1980, que señala que corresponde al SII:

la aplicación y fiscalización de todos los impuestos internos actualmente establecidos o que se establecieren, fiscales o de otro carácter en que tenga interés el Fisco y cuyo control no esté especialmente encomendado por la ley a una autoridad diferente.

En efecto, son estas dos normas las que impiden que la CGR se pronuncie sobre materias de naturaleza tributaria, absteniéndose en consecuencia

39 GUZMÁN BRITO 2014, 87. 
de emitir su opinión, situación que se ha producido en múltiples dictámenes y que podríamos concluir, constituye una línea jurisprudencial consistente del propio Órgano de Control ${ }^{40}$. De esta manera, extrayendo a la CGR del control de los actos que otorgan permisos de edificación, dejaríamos al Ministerio de Vivienda y Urbanismo a través de su DDU y sus respectivas Seremi, como los únicos órganos con atribuciones para interpretar administrativamente la LGUC y la OGUC, por una parte, y los IPT, por la otra. El efecto de sacar a la CGR será atenuar la posibilidad de contar con interpretaciones disímiles -y muchas veces contradictorias- en los procedimientos administrativos en que se tramitan autorizaciones urbanísticas, dejando solamente a dos órganos la atribución de interpretar administrativamente, dentro de su competencia, evitando por lo tanto las potestades concurrentes. Así, por ejemplo, en el caso que analizáramos, no se habría llegado a la decisión de ordenar a la Municipalidad de Vitacura que dejara de aplicar una norma vigente de su PRC por adolecer de ilegalidad, en tanto el IPT no fuera modificado según lo planteado en el Dictamen $N^{\circ} 11.765$, instrucción que, en mi opinión, se encuentra fuera de las atribuciones de la CGR y, además, llevada a cabo al margen de la Ley $N^{\circ} 19.880$. En este sentido, creo que es muy demostrativa la afirmación de Cordero Vega cuando señala que la CGR "también ha expandido sus competencias a materias donde las decisiones son difíciles de diferenciar de aquellas que corresponden a la Administración activa"41.

La modificación normativa que planteo no tiene por objeto sustraer del control de juridicidad los actos de las Direcciones de Obras Municipales, sino dar un orden lógico a una situación que viene hace tiempo produciéndose: la variedad de soluciones o criterios con los que se revisan los permisos y anteproyectos de edificación. Así, teniendo un órgano encargado de emitir las autorizaciones (DOM) y otros dos de naturaleza administrativa con capacidad para interpretar e instruir acerca de la aplicación de las normas urbanísticas, estimo que queda suficientemente resguardado el bien jurídico protegido que es la legalidad urbanística si el acto administrativo se conforma con sus pareceres. Y, el control posterior, también cuenta con diversas posibilidades: en sede administrativa, a través del reclamo contemplado en el artículo 12 de la LGUC en contra de las resoluciones emanadas del DOM, de conocimiento de la Seremi, y en sede judicial a través de los principales medios de impugnación: directamente a través del recurso de protección o, en la segunda fase a través del reclamo de ilegalidad municipal.

Por último, podemos afirmar que si bien la LGUC es suficientemente clara para dar por establecido por la interpretación en este ámbito solo compete a la DDU y a las Seremi, sin embargo y como ya hemos explicado, la propia CGR ha ampliado sus competencias para abocarse al conocimiento de temas propios de regulación y autorizaciones urbanísticas, como fue en el

40 Véase, por ejemplo, los Dictámenes Nos 1.269 de 2021; Nos 72.857, de 2009; 52.475, de 2012; 16.768, de 2013, y 43.358, de 2017, entre otros.

41 Cordero Vega 2010, 184-185. 
caso que revisamos, la CGR llegó incluso a pronunciarse sobre un acto trámite como es el acta de observaciones. Por ello, si la Ley $N^{\circ} 10.336$ se ha mantenido igual, debe reforzarse la LGUC y la orgánica del Ministerio de Vivienda y Urbanismo para dejar como únicos facultados para interpretar administrativamente a la DDU y a las Seremi, dado lo improbable que el Ente de Control haga un cambio de jurisprudencia sin que exista un cambio normativo en este sentido.

\section{Conclusiones}

A propósito del caso Santa Cruz Eyzaguirre Juan y otros con Municipalidad de Vitacura, hemos podido observar la existencia de un fenómeno que denominamos interpretación multinivel, esto es, la constatación de que en Derecho Urbanístico no existe una única fuente de la que emane la interpretación de la normativa aplicable, sino que estamos en presencia de distintos niveles escalonados de órganos con facultades hermenéuticas, esto es, DOM, DDU, Seremi, CGR y tribunales de justicia. En este sistema, las decisiones de los órganos inferiores pueden verse modificadas por los criterios que impongan los superiores. La materia urbanística es, además, considerada por los propios operadores y autoridades competentes como compleja, conforme lo reconoce la propia DDU.

Luego, la interpretación multinivel es problemática, por la combinación de dos elementos, (i) la variedad de pareceres que pueden darse en un asunto, al existir diversos órganos con competencias concurrentes, por lo que en un caso hipotético podríamos llegar a tener hasta cinco opiniones distintas sobre un mismo asunto; y (ii) que la decisión la tiene el órgano jurisdiccional, esto es, aquel cuyos integrantes controlan la actividad de la Administración de acuerdo a todo el Derecho vigente, es decir, no solo la normativa propiamente urbanística, siendo posible también que incorporen otras ramas del Derecho e incluso recurran a otros elementos para resolver (equidad, justicia material, principios generales del Derecho, etc.), en especial, cuando se trata del recurso de protección de garantías fundamentales.

La CGR al pronunciarse sobre la legalidad de un permiso de edificación, sobrepasa su competencia al declarar que el PRC no se conforma con la normativa aplicable y al ordenar a la DOM abstenerse de aplicar una norma vigente del PRC, lo que transgrede el artículo $3^{\circ}$ de la Ley $N^{\circ} 19.880$ en su inciso final, al gozar este tipo de acto administrativo de presunción de legalidad, imperio y exigibilidad. Lo que hace la CGR, al declarar que el IPT se aparta de la legislación vigente, es restarle eficacia mediante un medio no contemplado en la ley, vulnerando con ello también las disposiciones aplicables del procedimiento invalidatorio del artículo 53 de la Ley N 19.880.

La solución propuesta en este trabajo se enfoca en una modificación normativa que tenga por objeto reforzar las competencias de interpretación administrativa de la DDU y las Seremi, de forma tal que la CGR se abstenga 
de emitir pronunciamientos acerca de la legalidad de un permiso de edificación o anteproyecto, dejando siempre a salvo el control jurisdiccional.

\section{Bibliografía citada}

Aldunate Lizana, Eduardo y Cordero Quinzacara, Eduardo (2013). Estudios sobre el sistema de fuentes en el derecho chileno. Thomson Reuters.

CORDERO VEGA, Luis (2010). La jurisprudencia administrativa en perspectiva: entre legislador positivo y juez activista. Comentario desde el dictamen sobre la píldora del día después. Anuario de Derecho Público (1), 165-188.

CoRDERo Vega, Luis (2013). Nulidad y dictaminación de Contraloría: nuevas formas de declaraciones de ilegalidad. Comentario a las sentencias del caso CMPC. Anuario de Derecho Público UDP (1), 256-272.

Cordero Vega, Luis (2020a). El control de la Corte Suprema sobre los precedentes de la Contraloría General de la República. Revista Chilena de la Administración del Estado (4), 125-135.

CoRDERO Vega, Luis (2020b). El derecho administrativo chileno. Crónicas desde la jurisprudencia. DER Ediciones.

De la Cruz Millar, Alicia (2019). Contraloría General de la República: ¿Jurisdicción contencioso administrativa? DER Ediciones.

Evans EspiñeIRA, Ernesto y Poblete Ortúzar, Domingo (2012). Efectos que Produce la Declaración de Contrariedad a Derecho de un Acto Administrativo por parte de la Contraloría General de la República. En: VV.AA., La Contraloría General de la República. 85 años de vida institucional (1927-2012) (pp. 123-138). Contraloría General de la República de Chile.

GuZMÁn BRITo, Alejandro (2014). La interpretación administrativa en el derecho chileno. Thomson Reuters.

\section{Normativa citada}

Acta N 107 de 2017 [Corte Suprema]. Auto Acordado que Distribuye las Materias de que Conocen las Salas Especializadas de la Corte Suprema durante el Funcionamiento Ordinario y Extraordinario. 28 de julio de 2017.

Circular Ordinaria N ${ }^{\circ} 160$ [División de Desarrollo Urbano del Ministerio de Vivienda y Urbanismo]. Artículo $4^{\circ}$ de la Ley General de Urbanismo y Construcciones. Disposiciones generales, facultades y responsabilidades, División de Desarrollo Urbano. 12 de marzo de 2007.

Código Orgánico de Tribunales [COT]. Ley № 7.421 de 1943. 15 de junio de 1943 (Chile).

Código Tributario [CT]. Decreto Ley No 830 de 1974. 27 de diciembre de 1974 (Chile).

Constitución Política de la República. Art. 20. 17 de septiembre de 2005 (Chile).

Decreto $N^{\circ} 1$ [con fuerza de ley]. Fija el Texto Refundido, Coordinado y Sistematizado de la Ley N 18.695, Orgánica Constitucional de Municipalidades. 9 de mayo de 2006.

Decreto $N^{\circ} 7$ [con fuerza de ley]. Fija Texto de la Ley Orgánica del Servicio de Impuestos Internos y Adecúa Disposiciones Legales que Señala. 30 de septiembre de 1980.

Decreto $N^{\circ} 47$ de 1992 [Ministerio de Vivienda y Urbanismo]. Fija Nuevo Texto de la Ordenanza General de Urbanismo y Construcciones. 16 de abril de 1992. D.O. N 38.523.

Decreto N ${ }^{\circ} 458$ de 1975 [Ministerio de Vivienda y Urbanismo]. Aprueba Ley General de Urbanismo y Construcciones. 18 de diciembre de 1975.

Ley N ${ }^{\circ} 10.336$. Ley de Organización y Atribuciones de la Contraloría General de la República. 12 de mayo de 1952. D.O. No 22.261.

Ley N $N^{\circ}$ 19.880. Establece Bases de los Procedimientos Administrativos que Rigen los Actos de los Órganos de la Administración del Estado. 22 de mayo de 2003. D.O. N 37.570.

Oficio Ordinario N 940 de 2020 [Dirección de Obras Municipales de Vitacura]. Solicita pronunciamiento respecto de aplicación de uso de suelo "Embajada" para la propiedad 
ubicada en General John O'Brien N $² 677$, cuyo permiso de edificación se encuentra invalidado. 7 de octubre de 2020.

Resolución Exenta N³582 de 2018 [Contraloría General de la República]. Establece Estructura y Funciones de la División de Infraestructura y Regulación de la Contraloría General de la República. 2 de octubre de 2018.

Resolución N 59 de 1999 [Gobierno Regional Metropolitano de Santiago]. Aprueba Plan Regulador de la Comuna de Vitacura. Diario Oficial, 7 de diciembre de 1999.

Resolución No 104 de 2021 [Dirección de Obras Municipales de Vitacura]. Permiso de edificación de obra nueva. 14 de septiembre de 2021.

Resolución N³48 de 2020 [Dirección de Obras Municipales de Vitacura]. Ordena paralización total de obras que se ejecutan en la propiedad ubicada en calle General John O'Brien N ${ }^{\circ} 2677.16$ de marzo de 2020.

\section{Jurisprudencia citada}

Dictamen No 11.765 de 7 de abril de 2017 de la Contraloría General de la República.

Santa Cruz Eyzaguirre Juan y otros con Municipalidad de Vitacura (2019): Corte de Apelaciones de Santiago, 16 de enero de 2019 (Rol N³28-2018). Novena Sala. [Reclamo de ilegalidad municipal].

Santa Cruz Eyzaguirre Juan y otros con Municipalidad de Vitacura (2020): Corte Suprema, 13 de marzo de 2020 (Rol N 6.755-2019). Tercera Sala. [Recurso de casación].

\section{Abreviaturas}

Contraloría General de la República: $\quad$ CGR

División de Desarrollo Urbano del Ministerio de Vivienda y Urbanismo: DDU

Dirección/Director de Obras Municipales: DOM

Instrumento de Planificación Territorial: IPT

Ley General de Urbanismo y Construcciones: $\quad$ LGUC

Ordenanza General de Urbanismo y Construcciones: OGUC

Plan Regulador Comunal de Vitacura: PRC

Secretaría(s) Regional Ministerial(es) de Vivienda y Urbanismo: Seremi 
